\title{
INTERVENÇÕES DE REABILITAÇÃO URBANA E HABITACIONAL DA JUNTA DE ANDALUCÍA EM CIDADES LATINO-AMERICANAS (1984-2009): UMA EXPERIÊNCIA COMPARTILHADA ${ }^{1}$
}

\section{Urban And Housing Rehabilitation Interventions of The Junta De Andalucía In Latin American Cities (1984-2009): A Shared Experience}

\author{
Maria Cristina da Silva Schicchi \\ PUC-Campinas \\ cristina.schicchi@hotmail.com
}

\section{RESUMO}

A pesquisa analisa os principais projetos de reabilitação urbana e habitacional implementados pela Junta de Andaluzia (Espanha) na América Latina a partir dos acordos e convênios bilaterais de cooperação internacional, realizados entre 1990 e 2010. São discutidas as bases teóricas, os resultados e o papel de cada entidade (local e espanhola) nas diversas atividades realizadas. Inicia-se com uma breve contextualização do período de abertura democrática espanhola e a forma de abordagem dos problemas urbanos locais, passando pela discussão da transferência deste modelo de transição democrática para as cidades latino-americanas, após o período de redemocratização dos países do subcontinente, em meados dos anos 1980. Como conclusão, são analisadas as experiências mais recentes de reabilitação implementadas nas cidades andaluzas.

\section{Palavras-chave}

reabilitação urbana, América Latina, cooperação internacional, urbanismo

\section{ABSTRACT}

\footnotetext{
${ }^{1}$ Este artigo foi baseado no documento Actuación y participación de la Junta de Andalucía en proyectos de rehabilitación, preservación, recuperación urbana, cooperación para la divulgación cultural y gestión de los patrimonios preservados en las municipalidades latinoamericanas. Informe Final de Estancia Postdoctoral, realizado junto à Universidade de Sevilha, no Departamento de Historia, Teoría y Composición Arquitectónica, no biênio 2010 /2011, com supervisão do Prof. Dr. Eduardo Mosquera Adell e financiamento da FAPESP (Fundação de Amparo à Pesquisa do Estado de São Paulo). Parte do texto foi publicado nos Anais do XII Seminário de História da Cidade e do Urbanismo, em 2012.
} 
The research consists of an analysis of major urban and housing rehabilitation projects implemented by the Junta de Andalucía (Spain) in Latin America, based on bilateral international cooperation agreements established between 1990 and 2010. It discusses the theoretical bases, the results and the role of each entity (local and Spanish) in the many activities that took place then (and the urban and housing rehabilitation interventions). The text begins with a brief contextualization of the Spanish democratic reform and the new approaches on local urban problems in Spain, also discussing the transference of the democratic transition model and the conceptual and financial contributions to Latin American cities after the democratization period in the mid 80's and concluding with the analysis of the more recent rehabilitation experiences implemented in Andalusia cities, in which the participative management processes were adopted.

\section{Keywords}

urban rehabilitation, Latin America, international cooperation, urbanism

\section{Introdução}

Em estudo realizado sobre as experiências de reabilitação de áreas centrais de um conjunto de cidades brasileiras e latino-americanas, com significativo patrimônio urbano e arquitetônico ${ }^{2}$ - foi possível constatar uma intensa participação da Junta de Andalucía (Espanha) ${ }^{3}$ na difusão de programas e projetos de reabilitação, políticas de conservação e metodologias de gestão de áreas urbanas, por meio de acordos de Cooperação Internacional para o Desenvolvimento. Isto trouxe um particular interesse para a pesquisa que estava em curso, porque o trabalho de cooperação não é apenas uma forma de intercambiar conhecimentos, é também uma oportunidade de experimentar novas abordagens para os problemas. A atuação simultânea da Junta em cidades distintas permitiu o reconhecimento de questões comuns, do ponto de vista

\footnotetext{
2 O levantamento das experiências de cooperação da Junta de Andaluzia com países latino-americanos foi realizado durante dois períodos em 2010, em Sevilha. As visitas às cidades latino-americanas para levantamentos e entrevistas com os técnicos locais foram realizadas entre 2007 e 2011 , sendo parte de um trabalho de pesquisa mais amplo. Ambos foram realizados com financiamento de Auxílio Pesquisa FAPESP (2009-2011).

${ }^{3}$ A Junta de Andalucía é uma instituição de governo da Comunidade Autônoma de Andaluzia, criada nos anos 80. Disponível em: http://www.juntadeandalucia.es/fomentoyvivienda/portal-web/web/areas/vivienda , acesso em: 20/09/2012.
} 
histórico, sócio- cultural e problemas de gestão, para os quais foram adotadas, na maioria das vezes, soluções já utilizadas anteriormente nas próprias municipalidades espanholas. Após mais de vinte e cinco anos, hoje, observa-se a presença de técnicos e colaboradores da Junta em municipalidades de todos os países da América Latina, sem exceção.

Desta forma, foi necessário compreender como se insere a atuação da Junta de Andalucía no contexto dos acordos de Cooperação Internacional para o Desenvolvimento entre Europa e América Latina, após a redemocratização dos países latino-americanos e o ingresso da Espanha na Comunidade Europeia. Por um lado, é preciso compreender que o papel do vínculo histórico e cultural entre a América Latina e os países ibéricos, que há mais de três décadas ${ }^{4}$ impulsionou iniciativas de consolidação de uma identidade ibero-americana, e por outro, as mudanças no contexto geopolítico contemporâneo que permitiram que os países ultrapassassem limites continentais, no momento em que as cidades, cada vez mais, tomam a frente nos programas e projetos de cooperação para o desenvolvimento.

Portanto, compreender em que consiste e como opera a cooperação para o desenvolvimento da Junta de Andalucía com países latino-americanos, em especial, a atuação em projetos de reabilitação arquitetônica e de espaços públicos nos centros históricos, só foi possível a partir da análise de documentos, metodologias utilizadas e levantamento das intervenções realizadas em ambos os contextos.

A maioria dos países latino-americanos possui acordos de cooperação com Espanha através da AECID (Agência Espanhola de Cooperação Internacional para o Desenvolvimento), que anteriormente se denominava Instituto de Cooperación Iberoamericana (ICI), estava vinculado à política geral de Asuntos Exteriores do Governo central de Madrid e já tinha a América Latina como seu objetivo primordial. Porém, a atuação junto às municipalidades demandou projetos específicos no âmbito de uma diplomacia subnacional, da qual já participaram inúmeras cidades em todos os países latino-americanos, tais como Montevidéu, Buenos Aires, Quito, Lima, Havana, São Luís, Salvador, Potosí, Bogotá, Santiago do Chile, Valparaíso, etc.

Assim, foi necessário investigar os arquivos da própria Junta, em particular, os da antiga Consejería de Vivienda y Ordenación del Território (também com denominações anteriores como Consejería de Política Territorial ou Consejería de Obras Públicas y

\footnotetext{
${ }^{4}$ Se considerada como referência a data de criação do Instituto de Cooperación Iberoamericano (1979).
} 
Transportes), hoje Consejería de Fomento y Vivienda, Numa segunda etapa, foram também realizadas visitas às cidades que realizaram programas de cooperação com a Junta e coletadas informações, documentos e entrevistas com os gestores e técnicos de Buenos Aires, Valparaíso e Santiago do Chile.

Finalmente, é preciso assinalar que ao se empreender uma análise dos arquivos e dos produtos da cooperação internacional da Junta de Andalucía em distintos países, se esperava também encontrar uma sistematização de problemas comuns às cidades latinoamericanas. Ou seja, a experiência andaluza tornou-se ao mesmo tempo objeto e fonte de pesquisa desse trabalho.

Algumas questões pairam ainda em aberto, principalmente quanto aos motivos ou interesses que movem governos a se envolverem em cooperações com tantos países em simultâneo. Este questionamento é ainda mais necessário quando se observa, como no caso espanhol, que trata-se de uma forma de retomar relações com ex-colônias, algumas com governos ainda bastante dependentes de ajuda externa. Por outro lado, quando se observa a atuação em seu conjunto e os resultados dos projetos realizados, não se pode deixar de reconhecer a qualidade e seriedade com que os técnicos (de ambos os lados) se envolvem com o trabalho em cooperação. Estes, em resumo, são os aspectos que motivaram uma incursão mais detalhada sobre as experiências espanholas de cooperação com a América Latina.

\section{Cooperação Internacional para o Desenvolvimento e reabilitação de centros históricos}

Com a queda do Muro de Berlim, a entrada do modelo neoliberal e a economia de livre mercado, o sistema internacional experimentou grandes mudanças e o fenômeno da globalização implicou numa ampliação das relações internacionais, produto dos crescentes fluxos de informação, bens, serviços, capitais e migração de população. Segundo Ruiz Alanís (2009), a conformação de organismos internacionais e de blocos econômicos resultou em uma nova forma de defender os interesses comuns de alguns países, predominando, na maioria dos casos, os mais poderosos, tanto economicamente quanto militarmente. Por outro lado, o conceito de soberania sofreu uma erosão, o que acabou por reforçar a tendência dos países a aceitar políticas vindas de fora, sobretudo os subdesenvolvidos, para obter acesso a créditos e ajudas internacionais. 
A ideia de cooperação internacional aparece na Carta das Nações Unidas de 1945, incluída dentro dos propósitos e objetivos de cooperação em diferentes âmbitos (econômico social, cultural, humanitário) (ULLOA RIVERA, 2010). Em simultâneo, o termo "desenvolvimento" surge pela primeira vez em seu artigo 55. Além da atuação das Nações Unidas, a reconstrução da Europa após a segunda guerra também avançava com o Plano Marshall à frente, sem dúvida uma ajuda à reconstrução dos países do continente (DUCKWORTH-BATKER, 1971 apud ULLOA RIVERA, 2007).

Desta forma, segundo Muñiz de Urquiza (2005), a cooperação para o desenvolvimento foi concebida como a fórmula mais adequada para minimizar os efeitos do subdesenvolvimento tido como produto das desigualdades produzidas pelos fenômenos do crescimento acelerado dos anos 50-60, num cenário pós-colonial e de conflito entre blocos, que foi acentuado pelos efeitos posteriores da crise econômica dos anos 70 , frente a propostas que propugnavam uma modificação estrutural do esquema liberal de relações econômicas internacionais. Entretanto, com a finalidade de anular as causas primordiais do subdesenvolvimento ou minimizar os seus efeitos, a cooperação resulta, na maioria das vezes, numa solução que oferece mais um modelo de dependência vindo de países desenvolvidos. Para os autores, portanto, se trata de uma opção conservadora, ainda que tenha um elemento importante de solidariedade, fundamentado na interdependência - condição em que interesses contrários se conjugam para a consecução de algo comum - e no trato preferencial aos Estados mais pobres, novo enfoque incorporado às relações internacionais tradicionalmente concebidas até então como relações de poder (MUÑIZ DE URQUIZA, 2005).

Enquanto a cooperação internacional, em geral, consiste em uma atitude ou forma de comportamento dos Estados, a cooperação para o desenvolvimento vem determinada mais por seu conteúdo e finalidade. Esse caráter "finalista" é um dos recortes que definem a cooperação para o desenvolvimento, tanto como conceito na área do direito internacional, como na própria prática da cooperação. Outro aspecto importante é que são relações realizadas em termos preferenciais entre estados em situações desiguais de desenvolvimento. Desta forma, o paradigma de interdependência termina por encobrir ou minimizar as dimensões conflitantes das relações transnacionais entre Estados com disparidades de condições. 
Neste sentido, parece útil registrar a definição aceita por Moreno Martín (2003) sobre os conceitos de cooperação e de desenvolvimento. O primeiro pode ser definido como a ação que:

(...) persigue fines comunes o compartidos por varios grupos o sujetos y sus costos son repartidos entre los participantes. Más que una acción, la cooperación constituye una auténtica interacción social como lo indica la etimología del término: acción o trabajo realizado conjuntamente con otros. La idea de cooperación no supone que el fruto de lo realizado se vaya a repartir entre todos, sino que el objetivo perseguido es compartido por todos y que todos participan en el esfuerzo por conseguirlo (MARTÍN-BARÓ, 1983, apud MORENO MARTÍN, 2003).

O segundo conceito esteve mais associado, na história ocidental, a um modelo quantitativo de acumulação (capacidade de produção e consumo) do que ao referente ideológico fundamental da cultura contemporânea que é a garantia dos direitos humanos.

Porém, a nova perspectiva, adotada em especial por países emergentes e também defendida por ambientalistas, é a de limitar o consumo, em especial, dos países desenvolvidos, humanizando o conceito de desenvolvimento.

O surgimento de políticas de desenvolvimento sustentável e a diferença entre a "Pegada Ecológica" ${ }^{5}$ dos países desenvolvidos em relação aos países em vias de desenvolvimento, levou a que se recolocassem os modelos de crescimento e a ideia de urbanismo e planejamento do território, assim como os objetivos e as características dos modelos habitacionais. A própria crise de crescimento dos anos 1970 e o desencanto pela cidade derivada das expressões mais radicais do liberalismo econômico contribuíram para que o olhar se voltasse à cidade consolidada, em busca de sua densidade cultural, da recuperação de seus modelos de convivência, do desfrute de uma variedade maior de espaços públicos, de uma dependência menor dos transportes e, em especial, graças à singularidade, à refuncionalização apoiada no potencial identitário de seu patrimônio histórico, possível a partir da reabilitação. Tais fatores condicionaram as características das intervenções arquitetônicas e urbanas a partir dos anos 1990 e explicam a ênfase dada à reabilitação e ao conceito de reciclagem.

\footnotetext{
5 Trata-se de uma ferramenta de planejamento da sustentabilidade, bastante difundida pelo World Wildlife Fund (WWF). Disponível em: http://www.wwf.org.br/ Acesso em: 10/03/2014.
}

URBANA, V.6, no 8, jun.2014 - Dossiê: Cidade e Habitação na América Latina - CIEC/UNICAMP 
Neste novo marco, a convergência entre reabilitação do patrimônio urbano e desenvolvimento passou a ter maior importância nos acordos de cooperação internacional entre países, e, logo, entre comunidades e municipalidades, no âmbito da diplomacia subnacional, nos chamados acordos de segunda e terceira geração, iniciados em meados dos anos 1990. Porém, foi a partir do reconhecimento de semelhanças entre os problemas enfrentados pelos centros históricos, então, territórios delimitados, que uma estratégia de atuação em conjunto de cidades passou a definir o desenho de projetos de cooperação entre países do continente europeu e latino-americano e caribenho.

Segundo Mutal (2001), neste período, um projeto entre PNUD (Programa das Nações Unidas para o Desenvolvimento $)^{6}$ e Unesco lança uma convocação à cooperação internacional para assistência técnica aos governos latino-americanos, com um orçamento de USD\$20.000.000, em que foram criados 16 centros de conservação, os quais, após sete anos consecutivos já tinham formado 1.500 graduados em cursos de especialização.

As celebrações do V Centenário, protagonizadas pela Espanha se juntaram ao Projeto Regional PNUD/Unesco com sede em Lima, principalmente nos países de língua espanhola. Porém, o impulso à inovação na assistência financeira espanhola para a América Latina e o Caribe se deu a partir da política de cooperação do governo socialista $(P S O E)$, após o início do regime democrático e do ingresso do país na Comunidade Europeia, através da criação do 'Fundo V Centenário'. Tratava-se de um montante de 500 milhões de dólares destinado ao financiamento de projetos de desenvolvimento para atender às necessidades básicas dos estados latino-americanos, entre as quais, as de desenvolvimento urbano, habitação, conservação, restauração e aproveitamento do patrimônio cultural para o turismo (MUÑIZ DE URQUIZA, 2005).

Gutiérrez da Costa (2008), em discurso pronunciado no "Acto Homenaje a la Cooperación Internacional", realizado em Sevilha, reconta a história do envolvimento de vários intelectuais e artistas de ambos os continentes em diversas atividades promovidas pela Comunidade de Andaluzia, entre as quais, um concurso internacional de projetos cujo tema era a relação entre a arquitetura andaluza e a latino-americana, e os eventos programados para as festividades do V Centenário do Descobrimento, em 1992.

\footnotetext{
${ }^{6}$ Disponível em: www.pnud.org.br/pnud/, acesso em 10/12/2011.
} 
De forma geral, de 1974 a 1999, foram realizados inúmeros acordos de cooperação entre governos de cidades latino-americanas e caribenhas, BID e os governos de países europeus (ROJAS \& MOURA CASTRO, 1999). Além de investimentos na conservação de monumentos, os novos programas de cooperação destinariam recursos para a melhoria da infraestrutura e dos espaços públicos, para a conservação e reabilitação de edifícios privados e para o fomento de atividades econômicas e culturais. Passaram a incluir também os governos locais (estados e municípios) e entidades públicas vinculadas à promoção do desenvolvimento. No setor privado, promoveram a participação de grupos interessados na história e na cultura, já que tinham como pressuposto que a reabilitação permitiria atrair investidores e criar oportunidades para negócios e novos empregos.

\section{0 reencontro entre América Latina e Europa}

Em 1976, na etapa pré-constitucional espanhola, com o ingresso da Espanha no Banco Interamericano de Desenvolvimento (BID), se estabelecem as bases da atual assistência financeira no plano multilateral, institucionalizando-se uma relação que havia se iniciado no período anterior de expansão econômica espanhola (MUÑIZ DE URQUIZA, 2005). Coincide com o momento em que se reinauguram as relações entre Europa e América Latina, segundo Quevedo Flores (2007), quando em 1974 se realizam as primeiras Conferências Bianuais dos Parlamentos Europeu e Latino-americano.

Já em meados dos anos 1980 se celebram outros encontros-chave para a consolidação do processo de cooperação euro-latino-americano, como o Dialogo de San José (com países centro-americanos) em 1984, o diálogo com países andinos em 1985, o encontro União Europeia - Grupo do Rio7 em 1987 e, nos anos 1990, as reuniões de "Cúpulas de Chefes de Estado e de Governo - União Europeia - América Latina e Caribe".

O Tratado da União Europeia (TUE), firmado em Maastricht em 1992, constitui o marco das mudanças da cooperação para o desenvolvimento, onde se definiu uma política a ser compartilhada entre os estados membros (AYUSO POZO, 2001). Além dos temas principais propostos como prioritários pelo TUE, tais como o apoio aos processos democráticos, a luta contra a pobreza e o apoio às reformas econômicas, também se definiram três eixos transversais a incorporar em cada um deles: apoio à integração

\footnotetext{
7 O Grupo do Rio é uma instância de consulta política que trata dos temas de interesse comum para América Latina e Caribe cujos membros são: Argentina, Bolívia, Brasil, Chile, Colômbia, Equador, México, Panamá, Paraguai, Peru e Venezuela.
} 
regional, melhoria da educação em todos os níveis e gestão das interdependências (meio ambiente, energia, luta contra as drogas, transporte e outros).

O conceito de interdependência impôs novo desenho aos programas de cooperação internacional, com argumentos que misturam aspectos de caráter econômico, legal e de solidariedade. Segundo Ulloa Rivera (2010), a grande transformação sofrida pelo sistema internacional na última década impactou de maneira relevante a cooperação internacional e demandou uma estratégia de cooperação cujos princípios básicos eram a busca de eficiência e a otimização de recursos, além de potencializar seu caráter multiplicador.

Em contraste com o momento de pleno crescimento da economia espanhola e de outros países recém ingressados na $C E$, os desafios para a finalização dos anos oitenta e boa parte dos noventa enfrentados pelos países latino-americanos eram o ajuste estrutural, a aceleração do processo de industrialização e a abertura da economia ao exterior, assim como a maior competitividade da mesma. A América Latina tornou-se área prioritária de cooperação para a Espanha. Conforme balanço realizado em 1991, o país já havia impulsionado, dentro dos foros comunitários europeus, a realização de inúmeros Acordos de Cooperação de Terceira Geração com países e sub-regiões latinoamericanas (ÚBEDA-PORTUGUÉS, 2005).

Compreendido este processo histórico, entretanto, pairava ainda uma pergunta: porque realizar cooperação entre cidades, comunidades, países e, mais ainda, porque torná-la uma questão de estado, como ocorreu no caso europeu, e na Espanha em particular, nos últimos trinta anos?

A primeira resposta, encontrada em inúmeros discursos oficiais e comemorativos, além de estudos dedicados ao tema, evocava um "cooperar por princípio" (SÁNGHEZCUENCA, 2007), ou "por dever" (ULLOA RIVERA, 2010), ideias que não guardam relação com os processos de ajuda financeira operados por países desenvolvidos para subdesenvolvidos, que tiveram lugar após a Segunda Guerra Mundial.

A segunda explicação, ainda do ponto de vista mais geral, é que há uma corrente de pensamento na Nova Ordem Econômica Internacional (NOEI) que atribui às antigas metrópoles dos chamados países em desenvolvimento uma obrigação moral de cooperar, a partir da perspectiva de que sobre as potências coloniais pesaria um dever de reparar suas ex-colônias, seja porque o processo de colonização impediu o desenvolvimento daquelas nações, ao ter criado uma situação dependente, de exploração econômica e de 
aculturação em todos os sentidos, seja porque se considera que o desenvolvimento dos países industrializados se construiu sobre o subdesenvolvimento dos restantes (MUÑIZ DE URQUIZA, 2005).

Porém, no âmbito das relações entre os países da comunidade europeia, foi através da reaproximação com a América Latina, entre outros fatores, que a Espanha tentou se recolocar na Sociedade Internacional. A mudança de imagem do país em relação ao que havia representado a política exterior franquista e a aceitação do ingresso da Espanha na Comunidade Europeia devem muito a esta nova política exterior de projeção latino-americana, que, entre outros aspectos, possibilitou consolidar um discurso estratégico e coerente com o novo paradigma internacional de cooperação entre países. Em meio a muitas críticas e resistências por parte da própria comunidade latinoamericana $^{8}$, a política exterior espanhola foi pautada por lemas como "España, puente entre Europa y América". Este foi o primeiro passo, como se verá mais adiante, para transformar a gestão da transição democrática espanhola e as ações e projetos dela decorrentes em um modelo exportável para a América Latina.

\section{A experiência de reabilitação urbana nas cidades andaluzas}

Assim como muitas cidades europeias, nos anos 60 os centros históricos das cidades espanholas apresentavam condições de deterioração e obsolescência, decorrentes de planos de extensão urbana e formação de novos centros, causando graves problemas sociais e urbanos. O período desenvolvimentista (1959-1974) trouxe o abandono e a demolição de setores significativos em muitas cidades históricas por razões especulativas, com argumentos de necessidade de higiene social e melhorias funcionais. Este fato se somou à falta de instrumentos urbanísticos especificamente definidos para a cidade histórica, durante o período franquista, uma vez que a legislação e a técnica urbanística estavam pensadas para operar o crescimento e a extensão da cidade. Após a redemocratização, isto desencadeou um cenário de reivindicações sociais e culturais a favor da recuperação da cidade histórica e de aproximação às políticas europeias de reabilitação urbana, estabelecidas geralmente, em primeira instância, por poderes locais de matiz socialista, a exemplo do que ocorreu na cidade italiana de Bolonha. Segundo Pol Méndez (1993), é desta forma que as 'ideas-fuerza' de conservação e recuperação física

\footnotetext{
8 Sobre o posicionamiento contrário dos intelectuais ver DIETERICH, S. (Coordenador). Nuestra America contra el V Centenario. Emancipación e identidad de América Latina. 5a Edición. Navarra: Txalaparta Editorial, 1990.
} 
e social da cidade foram se configurando como solução para uma série de movimentos de reivindicação de melhorias das condições de vida na cidade.

Portanto, a experiência andaluza de reabilitação de centros históricos para habitação é fruto de políticas que se iniciaram na Espanha no início dos anos 1980, porém, com traços singulares, em muitos aspectos, em relação às políticas desenvolvidas em outros países europeus como França, Grã Bretanha ou Itália, embora as experiências realizadas durante os anos 70 deste último tenham sido uma referência inicial.

A estratégia denominada 'urbanística de la recuperación' se constituiria, então, em uma junção de reivindicações sociais, projetos políticos e alternativas culturais, adquirindo uma densidade ideológica que, como afirma Pol Méndez (1993), culminaria sendo integrada aos programas dos partidos de esquerda. Foram estas contingências que aproximaram a experiência espanhola da italiana, estabelecendo em $1983^{9}$ uma mudança na legislação vigente e a destinação permanente de financiamento estatal para a reabilitação do patrimônio residencial, que constituiu a mais significativa inovação nas políticas urbanas introduzidas pelo governo socialista a partir de 1982.

Efetivamente, em 1984, a Junta de Andalucía, assim como as demais comunidades espanholas, ganha autonomia plena no campo da política habitacional. O desenvolvimento de novas linhas de atuação e a experiência acumulada durante a década de 1980 se cristalizaram no I PLan Andaluz de Vivivenda y Suelo para o período de 1992-1995, documento principal com o qual se realiza a política de habitação em Andaluzia (CVOT-JA, 2008). Os planos mais significativos, segundo Pol Méndez (1993), se desenvolveram como um laboratório em cidades médias como Gijón, Salamanca, Lérida, Tarragona, Pamplona, Vitoria, Segovia, Barcelona e algumas partes de Madrid ou em intervenções nas bordas degradadas e desarticuladas de cidades cortadas por rios como Sevilha, Córdoba, Salamanca e Mérida, a partir de três abordagens fundamentais: o planejamento urbanístico, a reabilitação de habitações e as políticas de patrimônio histórico (TROITIÑO VINUESA, 2003).

São estas experiências de intervenção, vivenciadas dez anos antes de se iniciarem os novos acordos de cooperação com a América Latina que constituiriam exemplos a serem compartilhados com os governos locais latino-americanos, principalmente a partir do final dos anos 1990, com a aprovação da Ley 23/1998 de Cooperación Internacional para el Desarrollo que reconhece a autonomia das

\footnotetext{
9 Real Decreto sobre Rehabilitación del Patrimonio Residencial y Urbano de 1983. Pol Méndez, 1993, pág. 116, op.cit.
}

URBANA, V.6, no 8, jun.2014 - Dossiê: Cidade e Habitação na América Latina - CIEC/UNICAMP 
Comunidades Espanholas em matéria de cooperação descentralizada (SÁENZ DE LACUESTA, 2010) ${ }^{10}$.
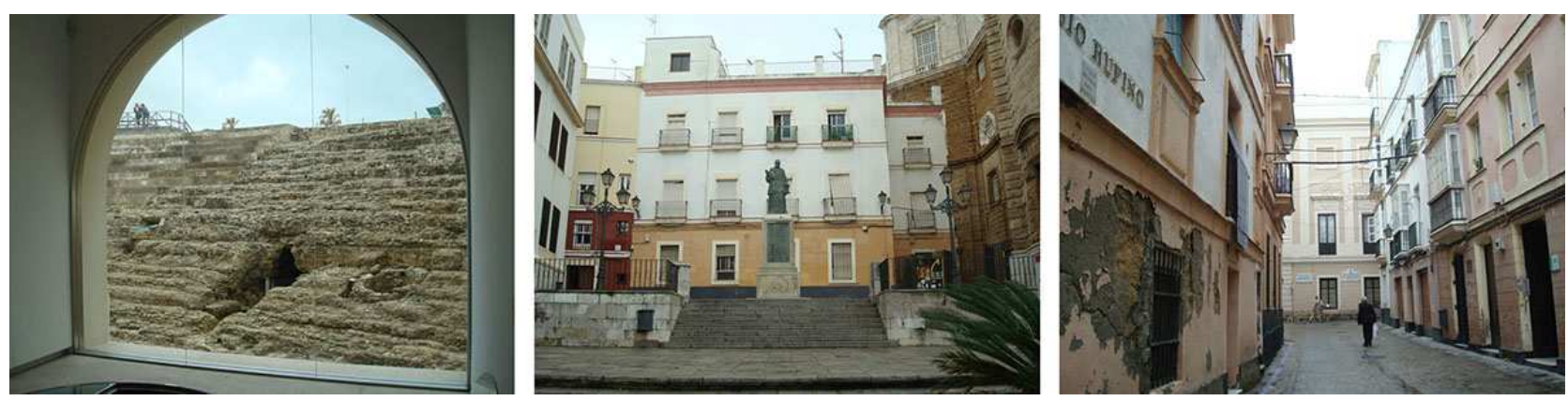

Figura 01. Intervenções no centro histórico de Cádiz (Espanha) iniciadas em 1999, com a recuperação de 5.204 habitações pela Oficina de Rehabilitación del Centro Histórico de Cádiz

(http://www.laciudadviva.org/obraspublicasyvivienda/epsa/laciudadviva/opencms/export/sites/laciudadviva/

04_experiencias/cvot/rehabilitacion_cccadiz/06CVOT_Rehabilitacixn_Centro_hco_de_Cxdizx.pdf) e

financiamento da Consejería de Vivienda y Ordenación del Território e a Empresa Pública de Suelo de Andalucía.

Fonte: Levantamento próprio, 2010.

No final dos anos 1990, estas experiências de reabilitação de cidades médias proporcionaram o amadurecimento de programas mais abrangentes do ponto de vista urbanístico e social, que incluíam também a experiência acumulada de atuação em cidades latino-americanas. Entre as cidades que sofreram intervenções, as reabilitações dos centros históricos de Cádiz (Figura 1) e de Albaicín em Granada (Figura 2) e dos bairros Trinidad-Perchel em Málaga e La Chanca e El Puche (Figuras 9 e 10) em Almería, se tornaram emblemáticas, por envolverem processos participativos e uma visão de reabilitação integral que inclui um trabalho de apoio social junto à população afetada, em geral de renda média e baixa e moradora há várias gerações nestes bairros. A estratégia definida foi a de envolver a iniciativa privada a partir do impulso de intervenções públicas. Para tal se criam nestas áreas as Oficinas de Rehabilitación, responsáveis pela gestão dos processos, com ações como a aquisição de terrenos para construção de novas habitações visando a manutenção da população original, ajuda aos proprietários para melhorar as condições de vida dos inquilinos e ajuda para pequenas reformas nas

\footnotetext{
10 Diretor de Estrategia y Comunicación de Cooperación do Instituto Andaluz de Patrimonio Histórico da Consejería de Cultura da Junta de Andalucía. No caso da Comunidade de Andaluzia, esta autonomia se consolida a partir da Ley 14/2003, de Cooperación Internacional para el Desarrollo e, pela Ley 2/2006, que criou a Agencia Andaluza de Cooperación Internacional para el Desarrollo (AACID).
} 
habitações (ROBERT ROMERO, 2010) ${ }^{11}$. Estes programas são financiados pela Junta de Andalucía e estão submetidos a uma legislação de habitação própria. As obras são realizadas pela Empresa Pública de Suelo de Andalucía (EPSA) e as intervenções nos espaços públicos e demais ações são feitas pela municipalidade, ou seja, numa ação concertada ${ }^{12}$.
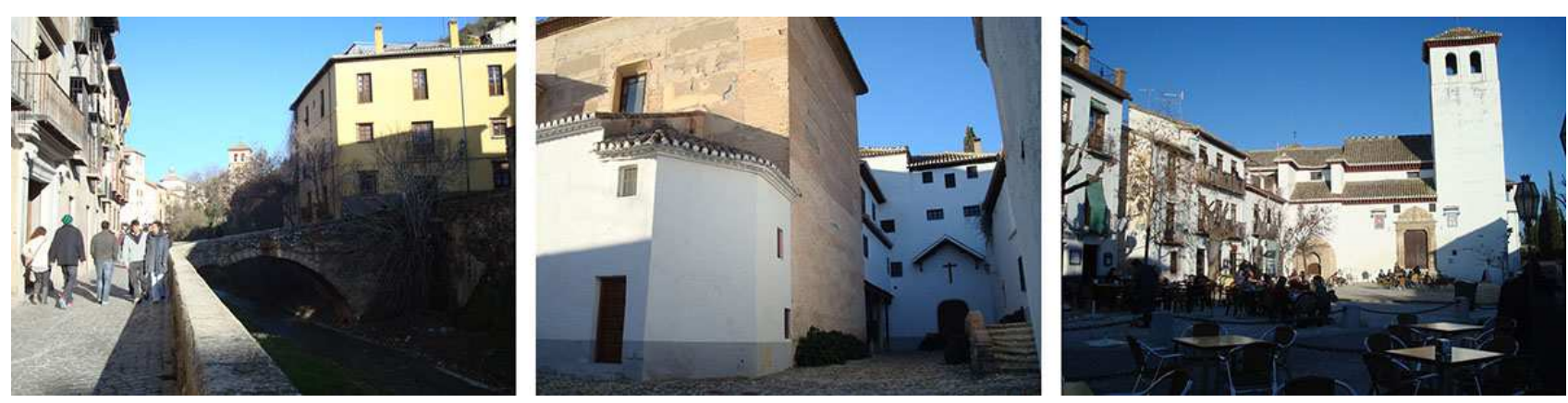

Figura 02. Intervenções no centro histórico de Albaicín (Granada, Espanha). Iniciadas em 2001-2002, com recuperação de 5.007 habitações pela Oficina de Rehabilitación del Centro Histórico de Albaicín (Patrimônioda Humanidade:http://www.laciudadviva.org/obraspublicasyvivienda/epsa/laciudadviva/opencms/export/sites/I aciudadviva/recursos/documentos/Familias_de_documentos/Experiencias/De_la_Consejeria/Rehabilitacion_d e_Centros_Historicos/Informacixn_complementaria_Albaicin.pdf) e financiamento da Consejería de Vivienda y Ordenación del Território e a Empresa Pública de Suelo de Andalucía. Da esquerda para a direita: vista do bairro a partir do canal; interior do bairro com construções reabilitadas; vista de praça reabilitada com bares e restaurantes.

Fonte: Levantamento próprio, 2010.

É importante ressaltar que a reabilitação habitacional tem sido um dos principais pontos das políticas públicas dos governos das comunidades espanholas. A constituição de um aparato administrativo atuante junto a áreas ocupadas por população de baixa renda também permitiu um controle dos problemas sociais, entre eles, os de segurança e emprego. No caso de Andaluzia, foi criado um fundo social para manutenção e melhoria da qualidade de vida da população com poucos recursos que mora nos centros das cidades. Por outro lado, é possível compreender a política de habitar a cidade histórica também como uma resposta aos fracassos do urbanismo contemporâneo, sendo esta uma das ideias que impulsionou, indistintamente, a cooperação com países mais ou menos necessitados de ajuda técnica na área, envolvendo ou não aportes financeiros.

\footnotetext{
${ }^{11}$ Arquiteta da Oficina de Reabilitação do Centro Histórico de Cádiz.

12 A Empresa Pública de Suelo de Andalucía (EPSA) se constitui em 1985 (Ley 1/1985, de 11 de Febrero, de Presupuesto de la Comunidad Autónoma de Andalucía), como uma Entidade de Direito Público. Disponível em:

http://www.juntadeandalucia.es/viviendayordenaciondelterritorio/epsa/web/html/informacion_institucional/

URBANA, V.6, no 8, jun.2014 - Dossiê: Cidade e Habitação na América Latina - CIEC/UNICAMP
} 


\section{A experiência compartilhada: intervenções da Junta de Andaluzia em países latino-americanos}

Uma vez compreendidos os processos de transformação ocorridos e a importância da retomada da "cidade construída", e após o levantamento de um conjunto de intervenções recentes espanholas nos centros históricos latino-americanos, surgiram novas indagações: por que teriam se estendido por tantas cidades em simultâneo? Ou, haveria um padrão nas intervenções realizadas, quanto aos agentes envolvidos, métodos de trabalho ou aportes financeiros? E, por último, que fatores contribuíram para que as cooperações espanholas com a América Latina fossem retomadas com mais vigor em meados dos anos 1980 ?

A trajetória da cooperação andaluza se inicia após o final do período franquista, em 1975, com a promulgação da Constituição Espanhola e a divisão do território em distintas comunidades autônomas em 1979 (CCAA). Desde este primeiro momento, o país foi governado pelo Partido Socialista Obrero Español (PSOE), cujo governo se inicia em 1982 e se mantém por quatorze anos, sendo que a Comunidade Andaluza tem sido governada pelo PSOE há mais de trinta anos, o que permitiu uma atuação continuada da Dirección General de Arquitectura y Vivienda, órgão estatal responsável pelas cooperações em matéria de reabilitação urbana com diferentes países.

A cooperação internacional com a América Latina se inicia com o Ministerio de Vivienda de Cuba e com a apresentação de arquitetos latino-americanos no Congresso de Arquitetura Vernácula em 1984, promovido pela AECI (Agência Espanhola de Cooperação Internacional) na cidade de Havana. O órgão interlocutor destas atividades foi o Centro Nacional de Conservación, Restauración y Museología (CENCREM) através da Cátedra Regional de Ciencias de la Conservación Integral de los Bienes Culturales y Naturales para América Latina y el Caribe da UNESCO (CRECI), com sede no Convento de Santa Clara, responsável, naquele momento, pela recuperação do centro histórico de Habana Vieja (MORENO GARCÍA, 2010) ${ }^{13}$. Nesta ocasião, a reabilitação da Plaza Vieja (Figura 3), que havia sido declarada Patrimônio da Humanidade (1982) era o objeto principal de discussão sobre a reabilitação do centro histórico e, aproveitando a presença espanhola no evento, os arquitetos cubanos propuseram, informalmente, que a Espanha colaborasse com a reabilitação da praça, como continuidade dos trabalhos de

\footnotetext{
13 Um dos arquitetos idealizadores da Cooperação Internacional da Junta de Andaluzia com países latinoamericanos.
} 
cooperação. O financiamento, aprovado pelo Parlamento Espanhol, abriu um precedente para a atuação espanhola em outros países latino-americanos.

\section{Quadro1. Protocolos e programas - Cuba (1993-2009)}

Fonte: Reprodução e tradução de dados obtidos em Cooperación Internacional. Consejería de Vivienda y Ordenación del Territorio. Fichas de Programas y Actuaciones por países. Junta de Andalucía, 2008. Elaboração própria.

\begin{tabular}{|c|c|c|c|c|}
\hline \multicolumn{5}{|c|}{ PROTOCOLOS E PROGRAMAS DE ATUAÇÃO - CUBA } \\
\hline Protocolo & La Habana & Reabilitação e outros & 21/10/1993 & 2 anos \\
\hline Programa Atuação & & $\begin{array}{l}\text { Guia Arquitetura. Publicações. Reab. } \\
\text { Santo Ángel; Reab. Malecón; Autoreab. } \\
\text { Habana Vieja }\end{array}$ & $21 / 10 / 1993$ & 1993-1994 \\
\hline Programa Atuação & La Habana e CCAA da Espanha & Reabilitação Malecón & $28 / 07 / 1994$ & \\
\hline Programa Atuação & La Habana, Of. Historiador & $\begin{array}{l}\text { Santo Ángel; Reab. Malecón; Parque } \\
\text { Metropolitano }\end{array}$ & $17 / 11 / 1995$ & 1996-1997 \\
\hline Programa Atuação & ANX - DPPF La Habana & Edição Guia de Arquitetura & $17 / 11 / 1995$ & \\
\hline Programa Atuação & $\begin{array}{l}\text { Instituto Planificación Física } \\
\text { Cuba; Parque Metropolitano }\end{array}$ & Plan Centro Habana. Parque Metropol. & 23/11/1999 & $2000-2001$ \\
\hline Programa Atuação & La Habana, Of. Historiador & Reab. Malecón. Explo Weiss. Publicações & $15 / 05 / 1998$ & 1998-1999 \\
\hline Programa Atuação & & Reab. Malecón. Concurso de Arquitetura & $07 / 03 / 2000$ & $2000-2001$ \\
\hline Protocolo & & Reabitação e Plaza Vieja & $23 / 11 / 2005$ & 5 anos \\
\hline Programa Atuação & & $\begin{array}{l}\text { Reab. S. Ignacio } 360 \text {; Publicação Plaza } \\
\text { Vieja }\end{array}$ & $23 / 11 / 2005$ & $2005-2009$ \\
\hline Protocolo & Municipio Santiago & Arquitetura, Habitação e Urbanismo & $02 / 11 / 1999$ & 2 anos \\
\hline Programa Atuação & & Guia Arquitetura; Reab. Cayo Granma & 25/11/1999 & $2000-2001$ \\
\hline Protocolo & & Arquitetura, Habitação e Urbanismo & $25 / 08 / 2002$ & 5 anos \\
\hline Programa Atuação & & $\begin{array}{l}\text { Reab. Cayo Granma e outros; Ordenação } \\
\text { Territorial }\end{array}$ & $07 / 12 / 2002$ & $2002-2004$ \\
\hline Protocolo & & Arquitetura, Habitação & $29 / 11 / 2005$ & 6 anos \\
\hline Programa Atuação & & Reab. Cayo Granma; publicação; expos. & $29 / 11 / 2005$ & $2005-2009$ \\
\hline Programa Atuação & & Reab. Barrio Santo Tomás & $14 / 09 / 2007$ & $2007-2009$ \\
\hline Protocolo & Município Trinidad & Arquitetura, Habitação e Urbanismo & 02/11/1999 & 2 anos \\
\hline Programa Atuação & & Guia Arquitetura & 25/11/1999 & $2000-2001$ \\
\hline Protocolo & & Arquitetura, Habitação e Urbanismo & $21 / 08 / 2002$ & 5 anos \\
\hline Programa Atuação & & Reab. Plaza del Calvario & $12 / 12 / 2002$ & $2002-2004$ \\
\hline Protocolo & & Arquitetura; Habitação & $30 / 11 / 2005$ & 6 anos \\
\hline Programa Atuação & & Plaza de las Tres Cruces & $30 / 11 / 2005$ & $2005-2009$ \\
\hline
\end{tabular}



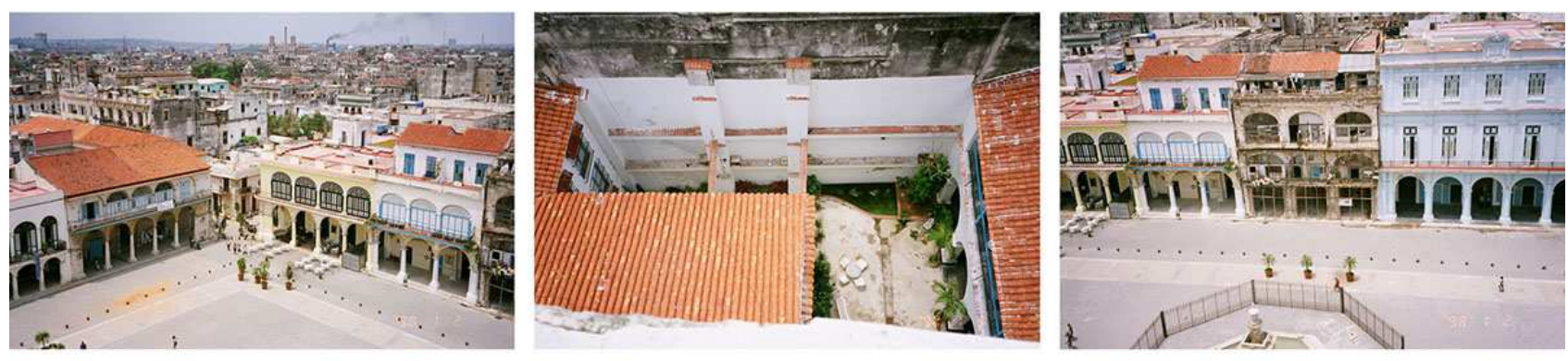

Figura 3. Intervenções na Plaza Vieja no centro histórico de La Habana (Cuba) realizadas pela Oficina del Historiador de La Habana a partir de 1993. Algumas construções foram reabilitadas com financiamento da cooperação entre a Consejería de Obras Públicas y Transportes de la Junta de Andalucía e a Oficina del Historiador, como a que se vê no centro da foto à direita (Calle San Ignacio 360), iniciada em 2006 e concluída em 2010.

Fonte: Levantamento próprio, 2007.

Por questões diplomáticas, cujo espaço aqui não permite detalhar, o financiamento aprovado acabou não sendo utilizado em La Habana e sim em Quito, através do contato entre o então Diretor do Escritório Regional da Unesco para "La Habana" - e os arquitetos andaluzes. Assim, em 1986, foi proposta a transposição do dinheiro para financiar a reabilitação da Casa de los Siete Patios em Quito.

Nos anos que se seguiram, vários arquitetos latino-americanos colaboraram como intermediários entre a Comunidade Andaluza e os seus respectivos países, cujo grande marco foi a criação do Premio Andalucía-América pela Consejería de Cultura da Junta de Andalucía. O núcleo de cooperação se formou, portanto, a partir da reunião de arquitetos renomados e pessoas comprometidas com a cooperação internacional (MORENO GARCÍA, 2010) $)^{14}$. Os diretores e técnicos envolvidos com a cooperação internacional foram unânimes na resposta sobre os motivos porque realizar cooperação: solidariedade e troca cultural (RODRÍGUEZ GALADÍ, 2010), por isso, a cada nova gestão, o compromisso era reiterado.

\footnotetext{
14 Segundo o arquiteto, entre estes estavam Ramón Gutierrez, Eduardo Alva, Mariano Arana, Rogelio Salmona, C. Lobo. Ao promover as exposições e publicações de seus trabalhos, a Espanha acabou possibilitando também o encontro e a troca de experiências entre os arquitetos latino-americanos, cujo espaço mais importante foi consolidado nos Seminários de Arquitetura Latino-americana (SAL), a partir de 1985.
} 


\section{Quadro2. Protocolos e programas de atuação - Equador (1990-2009)}

Fonte: Reprodução e tradução de dados obtidos em Cooperación Internacional. Consejería de Vivienda y Ordenación del Territorio. Fichas de Programas y Actuaciones por países. Junta de Andalucía, 2008.

Elaboração própria.

\begin{tabular}{|c|c|c|c|c|}
\hline \multicolumn{5}{|c|}{ PROTOCOLOS E PROGRAMAS DE ATUAÇÃO - EQUADOR } \\
\hline Protocolo & Quito Metropolitano & Reabilitacão/Fomento/Formação & 29/03/1990 & 4 anos \\
\hline Protocolo & & $\begin{array}{l}\text { Reabilitacão/Fomento/Formação } \\
\text { Urbanismo }\end{array}$ & 28/01/1994 & 4 anos \\
\hline Programa Atuação & & $\begin{array}{l}\text { Programa de reabilitação de habitações } \\
\text { Reab. Casa } 7 \text { Pátios - E Espaço Público. Leis de } \\
\text { Urbanismo/Parque Metropolitano. Bienal } \\
\text { de Arquitetura. Formação. Jornadas }\end{array}$ & $28 / 01 / 1994$ & $1994-1996$ \\
\hline Programa Atuação & & $\begin{array}{l}\text { Programa de reabilitação de habitações. } \\
\text { Reabilitação de edifícios: Casa } 7 \text { Patios - } \\
\text { Penadillo - La Higera. Espaço Público } \\
\text { Parque Metropolitano. Projeto Bairro } \\
\text { Mariscal/Sucre. Bienal de Arquitetura. } \\
\text { Formação / Jornadas }\end{array}$ & 29/05/1997 & $1997-2000$ \\
\hline Programa Atuação & MCD & Vários temas do PI. de Atuação de 29/05/97 & 15/03/1999 & \\
\hline Protocolo & & $\begin{array}{l}\text { Reabilitação/Fomento/Formação } \\
\text { Urbanismo }\end{array}$ & $05 / 07 / 2001$ & 4 anos \\
\hline Protocolo & & $\begin{array}{l}\text { Reabilitação/Fomento/Formação } \\
\text { Urbanismo }\end{array}$ & $05 / 07 / 2006$ & 5 anos \\
\hline Programa Atuação & & $\begin{array}{l}\text { Programa de reabilitação de habitações } \\
\text { Reab. Edifícios: continuação. PI. Esp. Centro } \\
\text { Histórico e PI. Esp. Bairro Mariscal/Sucre. } \\
\text { Plano de Habitação. Apoio Bienal Arquitetura } \\
\text { Formação/ Exposição }\end{array}$ & $05 / 07 / 2006$ & 2006-2009 \\
\hline Protocolo & $\begin{array}{l}\text { Cuenca - } \\
\text { Município }\end{array}$ & $\begin{array}{l}\text { Reabilitação/Fomento/Formação, } \\
\text { Urbanismo }\end{array}$ & $29 / 10 / 2002$ & $4+4$ anos \\
\hline Programa Atuação & & $\begin{array}{l}\text { Programa de reabilitação de habitações. } \\
\text { Ajuda à reabilitação privada. PI. Especial } \\
\text { do Centro Histórico. Formação. Publicações } \\
\text { Exposições }\end{array}$ & $26 / 06 / 2006$ & 2006-2009 \\
\hline Convenio & $\begin{array}{l}\text { Universidad Pontificia } \\
\text { Ecuador }\end{array}$ & $\begin{array}{l}\text { Centro de Estudos Núcleos Históricos } \\
\text { Cidades Latino-americanas }\end{array}$ & $17 / 12 / 1999$ & 2 anos \\
\hline
\end{tabular}


Do ponto de vista político, partindo das experiências de reabilitação realizadas nas cidades andaluzas, executadas pelo governo socialista, a arquitetura e o urbanismo passam a ser protagonistas de um processo mais amplo de atuação junto às comunidades, tornando-se a base para políticas de intervenção no território. Esta base se consolidou, de fato, a partir de uma produtiva aliança entre política e arquitetura, estabelecida para a constituição de uma nova imagem do poder autonômico andaluz, com o apoio de uma geração de arquitetos que ingressaram nos cargos públicos com o rigor profissional que haviam experimentado nas primeiras atuações municipais de esquerda, a partir de 1979. A Junta de Andalucía foi crucial para o desenvolvimento de tal aliança e um dos fatores chave foi a projeção exterior de alguns de seus arquitetos através das ações de Cooperação ${ }^{15}$.

Este enfoque encontra grande receptividade junto aos governos dos países latinoamericanos - a maioria, egressos de regimes de ditadura - em busca de novos ideais urbanísticos, não raro dentro de um ideário socialista de fortalecimento do poder e dos investimentos públicos sobre o território. Ou seja, a retomada da cooperação bilateral entre Espanha e América Latina coincide com os processos de abertura política nos países latino-americanos.

Por isso, depois da recuperação da Casa de los Siete Pátios em Quito e dos edifícios deteriorados localizados na Plaza Vieja de La Habana - cuja cooperação com Espanha é retomada após a entrada de Cuba no 'Regime Especial' - são inúmeros os exemplos de intervenção que se seguem nos centros ou bairros de cidades latinoamericanas voltados para a reabilitação habitacional, como é possível constatar nos Quadros 1 e 2, ou de atuações urbanísticas em várias escalas, como é o caso dos programas de atuação no Uruguai (Quadro 3).

\footnotetext{
${ }^{15}$ É importante ressaltar a coincidência de dois arquitetos em relevantes postos políticos de Andalucía, quer dizer, do consejero de Política Territorial (nomenclatura adotada naquele momento, depois de Obras Públicas, etc.) Jaime Montaner, como responsável máximo do governo andaluz neste assunto, e a partir da permanência em sua equipe e posteriormente, um trabalho mais ampliado, de José Ramón Moreno García, como diretor geral de Arquitectura y Vivienda. O mandato deste diretor geral implicou uma oportunidade determinante de criação e impulso político e administrativo da cooperação com a América Latina, através da reabilitação arquitetônica e urbana e de acordo com as características metodológicas, organizativas e operativas que se apresentam neste trabalho.
} 
Quadro 3. Protocolos e programas de atuação - Uruguai (1990-2008)

Fonte: Reprodução e tradução de dados obtidos em Cooperación Internacional. Consejería de Vivienda y Ordenación del Territorio. Fichas de Programas y Actuaciones por países. Junta de Andalucía, 2008. Elaboração própria.

\begin{tabular}{|c|c|c|c|c|}
\hline \multicolumn{5}{|c|}{ PROTOCOLOS E PROGRAMAS DE ATUAÇÃO - URUGUAI } \\
\hline Protocolo & Município Montevidéu & Reabilitação e urbanismo - Barrio Sur & 21/06/1990 & 4 anos \\
\hline Programa Atuação & & $\begin{array}{l}\text { Reab. Casa Verde, Formação, PI. Especial } \\
\text { Zona Sur }\end{array}$ & $21 / 06 / 1990$ & 1990-1991 \\
\hline Programa Atuação & ADD & Reabilitação de novos edifícios & 08/02/1991 & \\
\hline Programa Atuação & $A D D$ & Plan Director Saneamiento & 23/09/1991 & \\
\hline Programa Atuação & & $\begin{array}{l}\text { Reab., vários edifícios, Plan Director de } \\
\text { Saneamiento, Formação. }\end{array}$ & $16 / 03 / 1992$ & 1992-1993 \\
\hline Programa Atuação & ADD & Reab. de vários edifícios & 21/09/1995 & \\
\hline Programa Atuação & $A D D$ & Plan Territorial y Urbano de Montevideo & 26/10/1995 & \\
\hline Programa Atuação & & $\begin{array}{l}\text { Reab. Habitações, Ofic. Reab. Barrio Sur } \\
\text { Plan Territorial y Urbano, Edições/ } \\
\text { Formação }\end{array}$ & $31 / 01 / 1996$ & 1996-1998 \\
\hline Programa Atuação & & Continuação das atuações e atualiazação & 04/03/1999 & 1999-2001 \\
\hline Protocolo & & Reabilitação e Urbanismo & $07 / 07 / 2006$ & 5 anos \\
\hline Programa Atuação & & $\begin{array}{l}\text { Oficina de Rehabilitación Ciudad Vieja, } \\
\text { Espaços públicos: Ambito PE Arroyo } \\
\text { Miguelete y Ciudad Vieja - publicações, } \\
\text { Formação/ Rev. Plan Territorial y Urbano } \\
\text { Montevideo- Seminário }\end{array}$ & $28 / 01 / 2008$ & 2007-2008 \\
\hline Protocolo & Município Canelones & Reabilitação e Urbanismo & $03 / 08 / 2006$ & 5 anos \\
\hline Programa Atuação & & $\begin{array}{l}\text { Plan Territorial Costaplan,Normativa } \\
\text { Municipal, Espaços públicos. Catálogo } \\
\text { Edificação Rural/ Formação }\end{array}$ & $25 / 01 / 2008$ & $2007-2008$ \\
\hline Protocolo & $\begin{array}{l}\text { Ministerio Vivienda, } \\
\text { Territorio y M. Ambiente }\end{array}$ & Habitação e Urbanismo & $07 / 07 / 2006$ & 5 anos \\
\hline
\end{tabular}



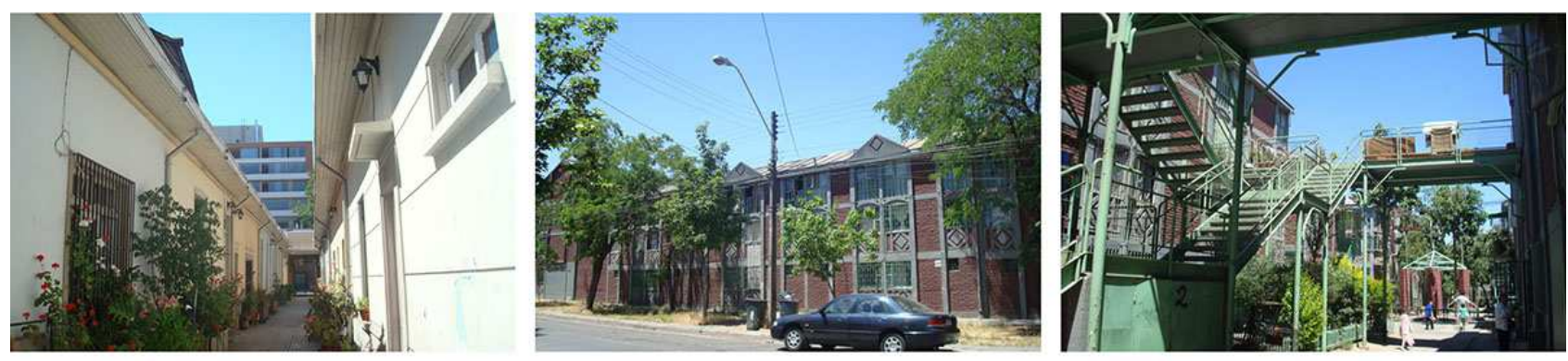

Figura 4. Intervenções nas Cités da Comuna de Santiago Centro (Chile). Realizadas entre 1997 e 1999 , sete destas comunidades foram reabilitadas com financiamento de cooperação entre a Junta de Andalucía e a Corporación para el Desarrollo de Santiago, como a da imagem à esquerda, a Cité Andalucía - Gorbea, construída em 1914 e reabilitada em 2000 e, nas duas fotos seguintes, as 178 habitações da Comunidad Andalucía, projeto do arquiteto Fernando Castillo.

Fonte: Levantamento próprio, 2010.

Entre os exemplos de reabilitação de edifícios de habitação social realizados pela Junta de Andalucía na América Latina estão intervenções nos cités y pasajes ${ }^{16}$ ocupações de quadras em forma de vilas ou passagens, construídas para a população operária no centro da cidade de Santiago - das quais, o quarteirão ocupado pela Comunidad Andalucía (Figura 4) e o edifício da Unión Obrera (Figura 5) em Valparaíso, anteriormente encortiçados, que contaram com a participação das comunidades, ambas no Chile, e a Manzana de San Francisco (Figura 6), exemplo equivalente ao chileno, no centro da cidade de Buenos Aires, são exemplos emblemáticos.
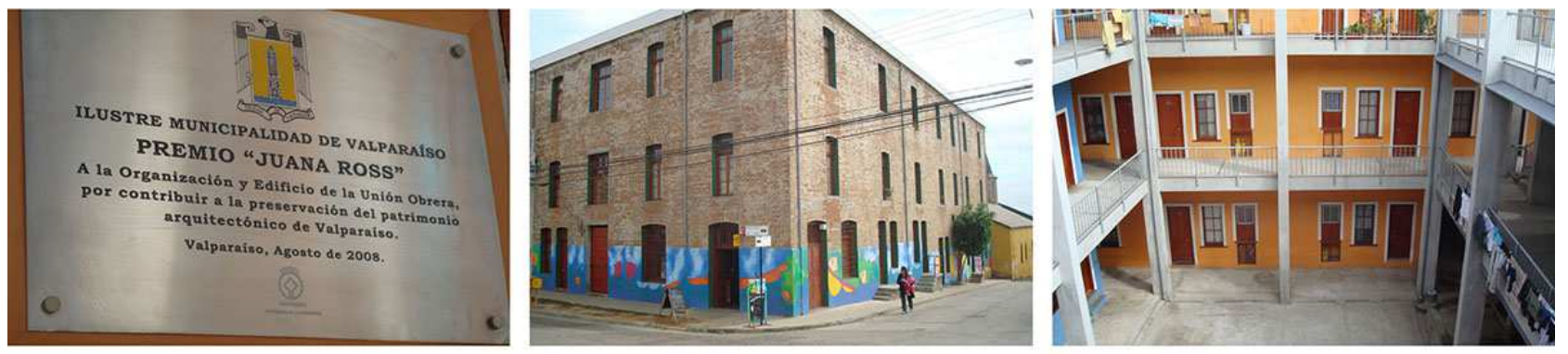

Figura 5. Intervenção de reabilitação em 34 habitações no edifício da Unión Obrera - Valparaíso (Chile). Edifício construído em 1898. As obras foram realizadas com financiamento de cooperação entre a Junta de Andalucía, a Municipalidade de Valparaíso e o Taller de Acción Comunitaria (TAC) e concluídas em 2008. Da esquerda para a direita: placa relativa ao Premio "Juana Ross" concedido ao trabalho de reabilitação;

fachadas do edifício; vista interna do pátio de acesso às unidades.

Fonte: Levantamento próprio, 2010.

\footnotetext{
16 Segundo o arquiteto Ariel Núñez Carreño, da municipalidade de Santiago:" Los Cités se originan a fines del SigloXIX y principios del sigloXX, como una respuesta al problema social, producido por la falta de viviendas para las clases más necesitadas, que comenzaban a poblar la periferia de Santiago, en busca de trabajo, product de las migraciones del campo y particularmente de la crisis del salitre en el norte del país. Inicialmente fue La Iglesia Católica, la que desarrolló el modelo de Cité, que luego fue seguido por el Estado, propiciándolo através de la Ley de Vivienda Obrera de 1906, que permitió finalmente a los particulars desarrollar con gran éxito este modelo de conjunto habitacional (NÚÑEZ CARREÑO, 2010).
}

URBANA, V.6, no 8, jun.2014 - Dossiê: Cidade e Habitação na América Latina - CIEC/UNICAMP 
A forma de organização da cooperação (entendida como uma missão) em matéria de reabilitação habitacional consiste em um primeiro contato com um grupo local - que pode ser uma universidade, uma municipalidade ou um governo nacional - pelo coordenador espanhol (sendo um para cada país) ${ }^{17}$. Este, geralmente é um arquiteto reconhecido e experiente (com atuações anteriores em arquitetura pública e como professor universitário), de forma que a partir deste contato inicial já seja possível traçar as linhas de atuação da cooperação que, em termos de investimento normalmente contribui com 50\%, em média (o valor pode variar em cada caso), do valor da reabilitação, sendo a porcentagem restante oriunda de contrapartidas de governos locais (de qualquer instância). No campo da cultura, estes investimentos são muito menores e a troca se dá basicamente a partir da organização e financiamento conjunto de cursos, eventos e workshops.

Outro produto importante da cooperação entre a Espanha e as cidades latinoamericanas são os guias de arquitetura. No início, eram realizados para suprir a falta de dados sistematizados sobre os patrimônios locais, para que os técnicos espanhóis (e, muitas vezes, também os locais) pudessem conhecer com mais profundidade a arquitetura local, inclusive para subsidiar a eleição dos edifícios a reabilitar ou restaurar. Com o tempo, acabaram se tornando um instrumento de atuação, uma forma de valorizar e inventariar o patrimônio, ao identificá-lo e divulgá-lo para os cidadãos e para os turistas. Hoje, constitui-se em um setor próprio da Consejería de Fomento y Vivienda (antiga Consejería de Vivienda y Ordenación del Território) para publicação de guias e planos-guias também das cidades andaluzas (RAMÍREZ MORENO, 2010) ${ }^{18}$.
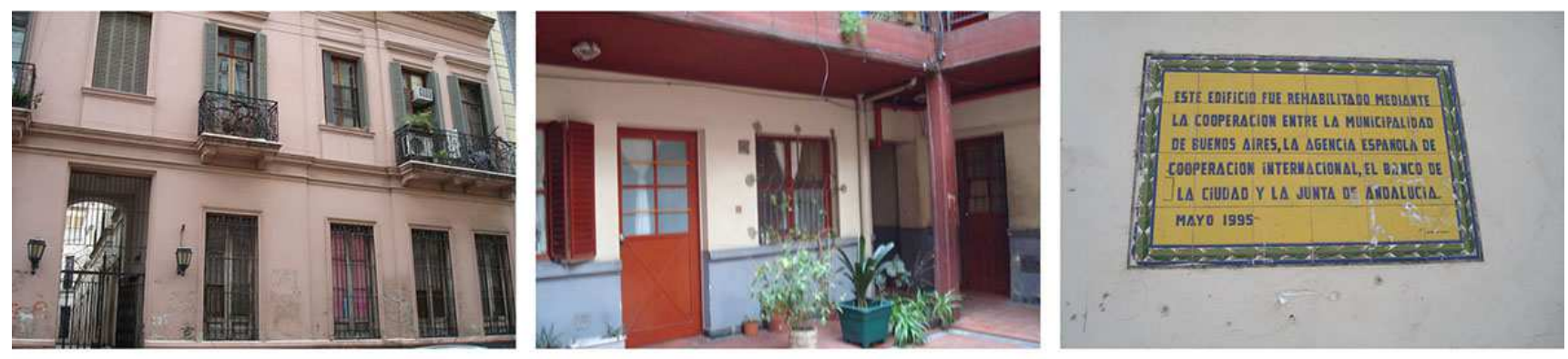

\footnotetext{
17 Os coordenadores realizam entre três e quatro viagens anuais ao país receptor.

18 Editor dos guias de arquitetura das cidades andaluzas e latino-americanas da Junta de Andaluzia.
} 
Figura 6. Intervenção de reabilitação em 94 habitações nos edifícios da Manzana de San Francisco. Situada no centro histórico de Buenos Aires (Argentina), construída na década de 1880, as obras foram realizadas de 1991 a 1995 através de financiamento de cooperação internacional entre a Junta de Andalucía/ ICI -Agencia Española de Cooperación, a Municipalidad de la Buenos Aires e o Banco Ciudad. Da esquerda para a direita: fachada para uma das ruas com entrada para pátio de acesso às unidades; vista interna a partir de pátio de acesso por outra rua; placa de inauguração da reabilitação.

Fonte: Levantamento próprio, 2011.

\section{Reabilitação de "barriadas" e a experiência incorporada em "La vuelta"}

A reabilitação urbana e habitacional constitui uma opção clara de política urbana para recuperação da "cidade construída" em Andaluzia, conforme já apontado. Desde 1984 foram desenhados programas específicos que permitiram solucionar o problema habitacional a partir da reabilitação de edifícios em áreas centrais (RODRÍGUEZ GALADÍ; GARCÍA FERNÁNDEZ; MORENO GARCÍA; GONZÁLES TAMARIT, 2010) ${ }^{19}$. Entretanto, a partir desta experiência, foi necessário aprofundar e desenvolver programas sob uma nova perspectiva de ação integral, dada a diversidade de condições dos bairros nas cidades andaluzas. Desta forma surgem os programas de Reabilitação de Centros Históricos e, em seguida, o de Reabilitação de Bairros e Barriadas (conjuntos habitacionais).

Em ambos, as intervenções têm como princípio a manutenção da população residente como melhor garantia para a preservação de uma "condição de cidade". A metodologia e alguns dos instrumentos utilizados nos programas e intervenções de reabilitação nas cidades latino-americanas foram, neste momento, incorporados nos programas habitacionais andaluzes. Como exemplo, podemos citar a criação de fundos rotativos, que já haviam sido utilizados em 1990 durante atuação no Uruguai, e os programas de autoconstrução assistida (GONZÁLEZ FUSTEGUERAS, 2010) ${ }^{20}$. Os próprios desenhos dos programas acabam aproximando as experiências entre as duas culturas, como por exemplo, as intervenções nos espaços públicos com participação da população realizadas em Villa Reina (Santiago, Chile) e em La Chanca (Almería), ou a construção de habitações nos fundos de pátios como modelo de densificação (GÓMEZ DÍAZ, 2010) ${ }^{21}$. Visedo Manzanares $(2010)^{22}$ reitera esta visão de que a metodologia é o principal legado passível de ser transferido em uma 'vuelta' ao território andaluz, principalmente porque o

\footnotetext{
19 Respectivamente: Chefe do serviço de Rehabilitación de Vivienda de la Junta de Andalucía; excoordenador da Cooperación Internacional da Consejería de Vivienda y Ordenación del Territorio e, os dois últimos, ex-coordenadores da Cooperação Internacional da Junta de Andaluzia - pioneiros neste enfoque da reabilitação do patrimônio cultural como resposta aos problemas sociais enfrentados nos centros históricos.

${ }_{20}$ Arquiteto, coordenador da Cooperação Internacional com o Uruguai e em Jerez de la Frontera.

${ }^{21}$ Arquiteto, coordenador da Cooperação Internacional com Cuba.

22 Arquiteto designado para reabilitação da residência na Calle San Ignacio 360, em Habana Vieja. Também realiza projetos de reabilitação em Cádiz.
} 
intercâmbio de conhecimentos exige um grau de confiança mútua das equipes que só é possível no âmbito de um trabalho de cooperação, ao reunir profissionais, políticos, pesquisadores e representantes da sociedade com objetivos comuns.

Do ponto de vista do urbanismo, a possibilidade de atuar desde a escala municipal até a nacional, como no caso das experiências realizada no Uruguai, possibilitou um exercício de teorização importante, conforme afirmou González Fustegueras (2010). Para Carrascal (2010) ${ }^{23}$, a Junta possui, de fato, um padrão de atuação que responde a problemas semelhantes em sua essência. Como exemplo, afirma que Cádiz, quando estava degradada tinha condições muito semelhantes às encontradas em São Luís (Maranhão, Brasil). Salmerón (2010) ${ }^{24}$ vê a cooperação com a América Latina como uma das principais experiências que possibilitaram a criação dos Indicadores de Conservação e Gestão de Cidades Patrimônio da Humanidade, que hoje se estendem à categoria de Paisagem Histórica Urbana (Memorandum de Viena, 2005).

Os últimos trinta anos de cooperação internacional culminaram com a criação de um instrumento permanente de comunicação e difusão comum destas experiências, desde 2008, que foram a revista e a página web "La Ciudad Viva"25 onde as experiências realizadas podem ser conhecidas. Este organismo já promoveu vários eventos comuns como, por exemplo, o Congreso Internacional La Ciudad Viva como URBS, realizado em 2009, em Quito, ou as Jornadas sobre "Obsolescências Urbanas: el caso de las barriadas residenciales", realizada em 2010, em Sevilha (Espanha). Neste último, foram apresentadas as experiências de reabilitação de conjuntos habitacionais construídos desde o final dos anos 50 em áreas mais afastadas do centro das cidades andaluzas, nos chamados "polígonos" residenciais, como o de San Martin de Porres, em Córdoba (Figura 7) ou o Polígono Sur (Figura 8), em Sevilha. Na reabilitação destes conjuntos, dos quais muitos se encontram deteriorados e com graves problemas sociais, foi utilizada a mesma metodologia desenvolvida para intervenções nos centros históricos andaluzes e latinoamericanos. Segundo Rodríguez Galadí \& Salmerón Escobar (2010) 26 : "Es un modelo de intervención de las políticas públicas, basado en la gestión integral y multidisciplinar, que utiliza la vivienda como recurso integrador del tejido urbano".

\footnotetext{
23 Arquiteto, coordenador da Cooperação Internacional com o Brasil, no Centro Histórico de São Luís (Maranhão), em 2008. Também coordenou projetos em Sevilha e Cádiz.

24 Arquiteto, coordenador da Cooperação Internacional com o Perú e do projeto de reabilitação de Albaycín (Granada).

25 La Ciudad Viva: http://www.laciudadviva.org/.

${ }^{26}$ Ao longo de vinte anos (1990-2010) se reabilitaram mais de duzentas mil habitações em Andaluzia.

URBANA, V.6, no 8, jun.2014 - Dossiê: Cidade e Habitação na América Latina - CIEC/UNICAMP
} 

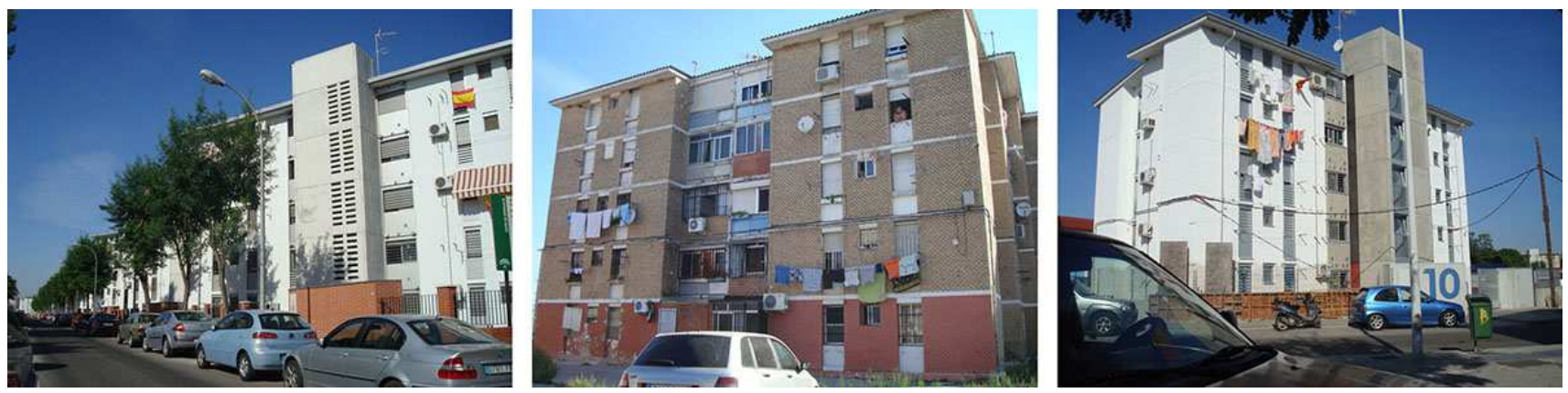

Figura 7. Reabilitação de 96 edifícios de San Martin de Porres (Córdoba - Espanha). Construído em 1959, as obras foram iniciadas em 2004 e ainda estão em andamento pela Consejería de Vivienda y Ordenación del Territorio e o Ayuntamiento de Córdoba. Da esquerda para a direita: a primeira foto mostra a reabilitaçao já concluída, com muros separando o conjunto de edifícios de uma comunidade; a segunda, um dos edifícios que ainda não havia sido reabilitado e a terceira, a finalização da reabilitação das áreas do térreo de um setor de edifícios.

Fonte: Levantamento próprio, 2010.

A partir dos anos 40, inúmeros conjuntos habitacionais foram construídos nas periferias das cidades espanholas, triplicando a população destas em 1970. Hoje, muitos são ocupados por população imigrante, oriunda dos países do norte da África, como é o caso de El Puche (Figura10), em Almería ${ }^{27}$, gerando problemas adicionais de convívio, fato que também explica a ênfase dada às cooperações com os países deste continente.

Algumas experiências precedentes em cidades andaluzas foram fundamentais para o desenho dos novos programas de recuperação de barriadas como o de La Chanca (Figura 9) também em Almería, território de resistência política durante o período de ditatura e forte organização comunitária, responsável por manter a população original no bairro após as intervenções (CVOT, 2008) ${ }^{28}$.

\footnotetext{
27 Mais de $60 \%$ da população é de imigrantes, dos quais, mais de $95 \%$ são provenientes do Marrocos (Mayor \& Vinuesa, 2009).

28 Entre as principais cidades que empreenderam intervenções de barriadas estão: Almería: Chanca, Puche; Cádiz: Cerro del Moro, El Saladillo- La Piñera de Algeciras; Córdoba: San Martín de Porres; Granada: Almanjayar; Huelva: Marismas del Odiel; Jaén: Polígono las Lagunillas-Puerta de Madrid Andújar; Málaga: Las Flores; Sevilla: Polígono Sur, Parque Alcosa $1^{\text {a }}$ Fase, Barrio Pudio de Coria del Río.
} 

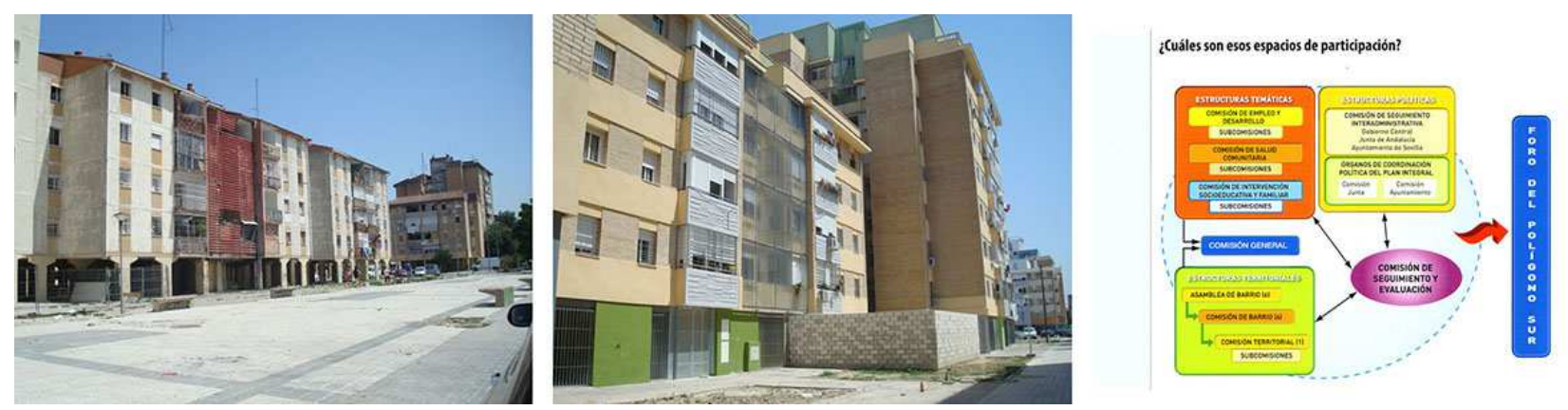

Figura 8. Reabilitação de 7.000 habitações do conjunto Polígono Sur (Sevilha - Espanha). Com população de 32.480 habitantes e construído nos anos 1970, as obras do Plan Integral foram iniciadas em 2003. Nas imagens, a partir da esquerda: edifícios em obras e recuperação do espaço público; imagem das obras concluídas com incorporação de soluções de apropriação dos moradores; detalhe do painel com organograma da gestão participativa proposta pelo Foro del Polígono Sur.

Fonte: Levantamento próprio, 2010.
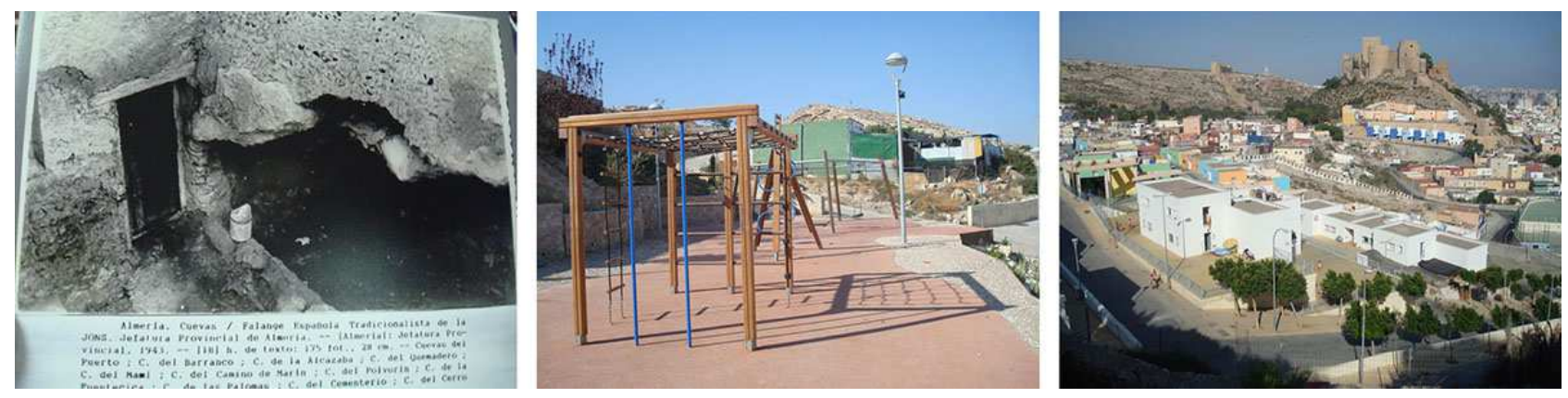

Figura 9. Intervenções do Plan Especial de Reforma Interior de La Chanca. Bairro histórico extramuros da Alcazaba de Almería - Espanha, cuja origem remonta ao século X. Uma das primeiras experiências de reabilitação com participação dos habitantes. Nas imagens, a partir da esquerda: uma das "cuevas" que foram fechadas e cuja área externa foi transformada em espaço público (ao centro); à direita, vista das novas construções nas encostas da Alcazaba.

Fonte: Levantamento próprio, 2010.
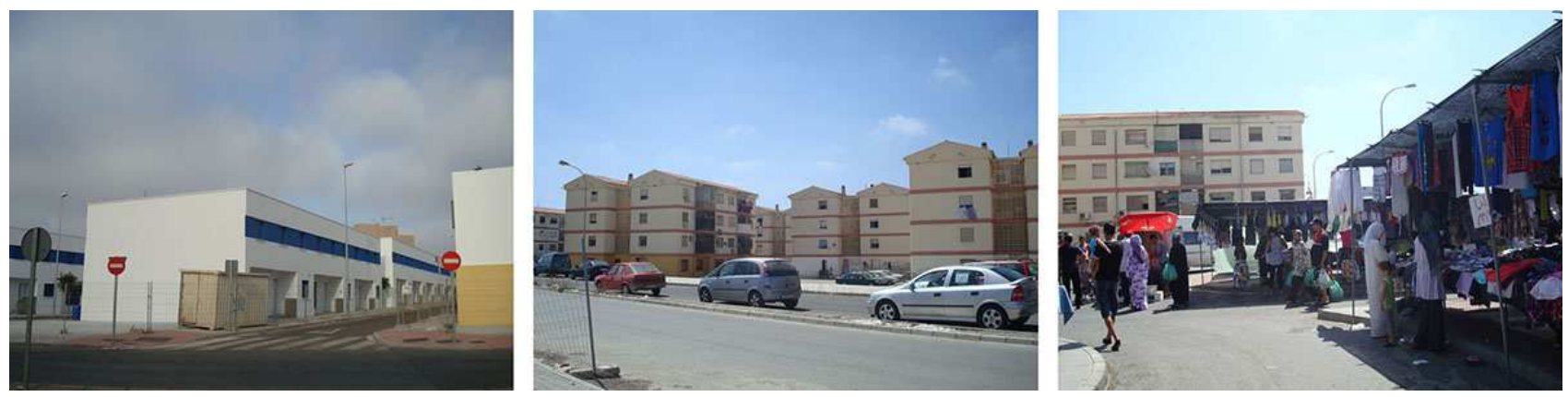

Figura 10. Reabilitação Integral do bairro de El Puche - Almería (Espanha). Com 3.000 habitantes, feita através de convênio entre Consejería de Obras Públicas y Transportes y el Ayuntamiento de Almería e Empresa Pública del Suelo de Andalucía, iniciada em 2006. Nas imagens, a partir da esquerda: construções do projeto sócio-educativo Cuido mi casa, cuido mi barrio, dentro do Programa Pedagogía del Hábitat; edifícios reabilitados no centro; à direita, feira popular semanal.

Fonte: Levantamento próprio, 2010. 


\section{Considerações finais}

O trabalho procura demonstrar que a cooperação internacional entre a comunidade de Andaluzia (Espanha) e as cidades latino-americanas nasce da coexistência de dois fatores: a simultaneidade dos processos em curso nas cidades, de forma mais geral, sob o novo marco de interdependência de desenvolvimento que caracteriza a Sociedade Internacional contemporânea, e a similaridade de uma parte significativa das transformações políticas, econômicas e espaciais vividas pela Espanha e pelos países latino-americanos em seus respectivos períodos pós-democratização, como a conquista de autonomia local das gestões, possibilitando acordos bilaterais a partir de uma diplomacia subnacional.

Estes fatores foram fundamentais para alterar a prática difundida até meados dos anos 80, em que a "ajuda para o desenvolvimento" era uma via de sentido único, do hemisfério norte para o sul, e o próprio conceito de desenvolvimento, antes associado a uma ampliação dos níveis de eficiência e bem estar material.

Neste contexto é que se inserem os trânsitos ou 'transferências' em matéria de reabilitação habitacional, dentro de Acordos de Cooperação para o Desenvolvimento. A preocupação com o processo, buscando compartilhar metodologias, que envolvam população, técnicos e políticos locais, além de ter uma "finalidade comum" e compartilhada (inclusive custos), pode viabilizar a construção de um ideário urbanístico para além das divisas nacionais ou continentais.

Outra questão apontada foi a adoção da reabilitação do patrimônio construído e social como política de intervenção no território pela Comunidade Andaluza como um caminho sem volta, que se opõe aos postulados urbanísticos modernos que prevaleceram durante o século $X X$. Evidência disto é a extensão dos mesmos procedimentos para a reabilitação dos conjuntos habitacionais modernos construídos no pós-guerra (barriadas). A ação pública não se ocupa mais do desenho da extensão da cidade e sim de "consolidar cidade". Neste sentido, as atividades realizadas pela cooperação internacional espanhola nas cidades latino-americanas podem ter contribuído para consolidar tal postura, na medida em que ampliaram o espectro de experiências e soluções para os problemas habitacionais comuns detectados (nas áreas centrais de cidades de ambos continentes) e os novos enfrentamentos demandados pelas áreas periféricas.

Os acordos de cooperação internacional podem ser entendidos sob duas perspectivas distintas. Por um lado, no âmbito dos governos nacionais, podem ensejar 
interesses econômicos e geopolíticos, tais como a possibilidade da Espanha se consolidar como país doador frente à Comunidade Europeia, ou mesmo a oportunidade de estabelecer a América Latina como o grande receptor preferencial dos produtos europeus, dentro de uma política de expansão comercial. Por outro, quando são operados nas instâncias subnacionais (municipais, por exemplo) e, principalmente, em matéria de desenvolvimento urbano, são pautados pelas equipes, formadas por arquitetos e outros profissionais qualificados, comprometidos ideologicamente com a cooperação, com um sentido de alteridade e solidariedade, revelando dimensões de intercâmbio técnico e cultural impossíveis de serem pensadas em circunstâncias normais de gestão.

Apesar do uso mais corrente do termo "transferência", menos ideológico que "ajuda", para denominar as ações realizadas nos países receptores, a cooperação ainda é pautada por um tratamento preferencial a partir do status de desenvolvimento dos países (segundo classificação da própria Unesco), restando avaliar ainda, em futuras pesquisas, de forma mais abrangente, se a participação dos agentes locais foi real, em todos os casos, ou diretamente proporcional ao grau de debilidade econômica, desintegração social ou desordem política dos mesmos, uma vez que não há homogeneidade destas condições na América Latina, o que explicaria inclusive o maior ou menor interesse e facilidade de acesso aos programas de cooperação para determinados países.

Além disso, restrita ao âmbito de intervenções nos patrimônios construídos ou em reabilitações habitacionais, muitas vezes a atuação dos técnicos espanhóis não enfrenta diretamente os problemas de planejamento local ou aspectos políticos inerentes à gestão, embora certas contingências políticas locais influam na maior ou menor aceitação da participação externa via cooperação internacional. Isto permitiu que em alguns países a cooperação se mantivesse por mais de vinte e cinco anos, com atuações consecutivas em várias cidades ou comunidades e em âmbitos mais abrangentes, como na elaboração de planos urbanos de médios e longos prazos, assim como na formação permanente de técnicos locais, enquanto em outras, se restringiu apenas ao período de execução de um ou dois projetos. Tal condição, por um lado, se reflete na continuidade dos processos iniciados e na sustentabilidade das intervenções, já que estas dependem da adesão permanente dos gestores, moradores e políticos locais e, por outro, pode produzir uma dependência permanente das comunidades receptoras de aportes externos 
para a solução dos problemas e a desvalorização de soluções resultantes de processos de discussão e decisão locais. Esta avaliação, de forma sistematizada, entretanto, não foi possível realizar no âmbito desta pesquisa.

\section{Referências}

AYUSO POSO, Anna (2001). La cooperación para el desarrollo de la Unión Europea en América Latina. La acción española ante un pasado umbrío y un futuro incierto. Revista d'Afers Internacionals, núm. 54-55. Barcelona: Fundació CIDOB, p. 85-109. CARRASCAL, Fernando (2010). Entrevista concedida ao autor(a), Sevilha, Janeiro. CVOT-JA (2008). Consejería de Vivienda y Ordenación del Territorio. Junta de Andalucía. Rehabilitación Integral de Centros Históricos. La Ciudad Viva - Experiencias, 2008. Disponível em: http://www.laciudadviva.org/export/sites/laciudadviva/04_experiencias/cvot/rehcenhis /centros_historicos_todo.pdf. Acesso em 23/04/2012.

GARCÍA FERNÁNDEZ, Emílio (2010). Entrevista concedida ao autor(a), Sevilha, Julho. GÓMEZ DÍAZ, Francisco (2010). Entrevista concedida ao autor(a), Sevilha, Janeiro. GONZÁLEZ FUSTEGUERAS, Manuel (2010). Entrevista concedida ao autor(a), Jerez de la Frontera, Julho.

GONZÁLEZ TAMARIT, Luis (2010). Entrevista concedida ao autor(a), Sevilha, Julho. GUTIÉRREZ DA COSTA, Ramón (2008). Cooperación. "Un camino de ida y vuelta". La Ciudad Viva nº1. Coordinación por la Dirección General de Vivienda y Arquitectura. Sevilla: Junta de Andalucía, p.90-95. Disponível em: www.laciudadviva.org Acesso em 13/12/2013.

MORENO GARCÍA, José Ramón (2010). Entrevista concedida ao autor(a), Sevilha, Julho. MORENO MARTÍN, Florentino (2003). Cooperación al desarrollo: Conceptualización psicosocial. Intervención Psicosocial. In Revista sobre igualdad y calidad de vida. Vol. 2 (1) España: Colegio Oficial de Psicólogos de Madrid, 10 páginas. MUÑIZ DE URQUIZA, María (2005). La cooperación para el desarrollo con América Latina en el marco de la política exterior de la España democrática. Garrido, Roberto Mesa (Director). Tesis Doctoral. España: Universidad Complutense de Madrid. MUTAL, Sylvio (2001). Ciudades y centros históricos de América Larina y el Caribe: 50 años de trayectoria (1950- 1999). In Carrión, Fernando (editor) Centros Históricos de 
América Latina y el Caribe. Quito: Flacso Ecuador/Ministerio de Cultura y Comunicación de Francia/Unesco/BID, p.113-138.

NúÑEZ CARREÑO, Ariel (2010). Entrevista concedida ao autor(a), Santiago do Chile, Novembro.

POL MÉNDEZ, Francisco (1993). "La Recuperación de los centros históricos de España". In Jornadas de Estudio Recuperación de centros históricos. García, Silvestre M. (coord.). Almería: Instituto de Estudios Almerienses, p. 109-150.

QUEVEDO FLORES, Jorge (2007). El espacio eurolatinoamericano 1992-2007: una estrategia efectiva de Política Exterior Común hacia América Latina. Tesis Doctoral. Facultad de Ciencias Políticas y Sociológicas. Madrid: Universidad Complutense. RAMÍREZ MORENO, Nicolás (2011). Entrevista concedida ao autor(a), Sevilha, Julho. ROBERT ROMERO, María del Mar (2010). Entrevista concedida ao autor(a), Cádiz, Julho. RODRÍGUEZ GALADÍ, José (2010). Entrevista concedida ao autor(a), Sevilha, Julho. RODRÍGUEZ GALADÍ, José I.; SALMERÓN ESCOBAR, Federico (2010). "Rehabilitación integral de los centros históricos andaluces. In Edificación sostenible. Revitalización y Rehabilitación de Barrios. Madrid: Sustainable Building Conference (SB10mad). ROJAS, Eduardo; MOURA CASTRO, Cláudio de (1999). Préstamos para la conservación del património histórico urbano - Desafíos y oportunidades. Informe. Washington D.C.: BID. Disponível em: http://publications.iadb.org/bitstream/handle/11319/5313/Pr\%C3\%A9stamos\%20para\% 20la\%20conservaci\%C3\%B3n\%20del\%20patrimonio\%20hist\%C3\%B3rico\%20urbano.pd f?sequence=1. Acesso em 13/12/2013.

RUIZ ALANÍS, Leobardo (2009). Las relaciones internacionales de los municipios. In Convergencia Revista de Ciencias Sociales, vol.16 núm.49, enero-abril. Toluca: Universidad Autónoma del Estado de México. Disponible en: http://www.redalyc.org/articulo.oa?id=10504910. Acceso en 02/02/2011.

SÁENZ DE LA CUESTA, Héctor (2010). La acción cultural exterior desde las Comunidades Autónomas. La Acción Cultural Española en el Exterior. (Orig. Dat.). Entrevista concedida ao autor(a), Sevilha, Julho.

SALMERÓN ESCOBAR, Pedro (2010). Entrevista concedida ao autor(a), Sevilha, Janeiro. SÁNCHEZ-CUENCA, Ignacio (2007). Cooperar por principio. In Revista Internacional de Sociología (RIS) Vol. LXV, n46, Enero-Abril, p.11-35. 
TROITIÑO VINUESA, Miguel Ángel (2003). La protección, recuperación y revitalización funcional de los centros históricos. In Capel, Horacio (org.) - Ciudades, arquitectura y espacio urbano. Instituto Cajamar, sem local de edição, p. 131-160. ÚBEDA-PORTUGUÉS, José Escribano (2005). El papel de España en la evolución de las relaciones internacionales entre la Unión Europea y América Latina (19851995). Tesis doctoral. España: Universidad Complutense de Madrid.

ULLOA RIVERA, Luis (2010). La cooperación internacional en la era de la globalización. Ciudad de México: Instituto Politécnico Nacional, 128 pág.

VISEDO MANZANARES, Fernando (2010). Entrevista concedida ao autor(a), Cádiz, Julho. VV.AA. (2008) Consejería de Vivienda y Ordenación del Territorio. La Rehabilitación Integral de Barrios. In La Ciudad Viva - Experiencias. Sevilla: Junta de Andalucía. Disponível

em:http://www.laciudadviva.org/export/sites/laciudadviva/04 experiencias/cvot/rehbar/ barrios.pdf. Acesso em 20/03/2012. 